\title{
S
}

Research article

2020 | Volume 8 | Issue 2 | Pages 78-86

ARTICLE INFO

Received

April 04, 2020

Revised

June 07, 2020

Accepted

June 09, 2020

Published

July 13, 2020

*Corresponding author

Muhammad Ali Shah

E-mail

dralishah50@gmail.com

Keywords

Avian coccidiosis

Vaccine

Immunity

Poultry

Molecular vaccines

How to cite

Shahid RA, Shah MA, Riaz A.

Advancements in research related to vaccination against avian coccidiosis. Sci Lett 2020; 8(2):78-86
Open Access

\section{Advancements in Research Related to Vaccination Against Avian Coccidiosis}

\author{
Raza Ali Shahid, Muhammed Ali Shah*, Aayesha Riaz \\ Department of Parasitology and Microbiology, Faculty of Veterinary and Animals Sciences, \\ PMAS Arid Agriculture University, Rawalpindi, Pakistan
}

\section{Abstract}

Coccidiosis is a fatal disease of poultry, caused by Eimeria species and considered the most prominent and destructive disease within all protozoal diseases. Chemotherapy is considered the main preventive strategy against coccidiosis. Chemotherapy is partially successful and has many drawbacks as it is practiced after the outbreak of disease, until then coccidiosis causes huge production and health losses. As an alternative, prophylactic measures like vaccination and management betterment are of eminent importance and can help to overcome this disease. Vaccination can induce antibodymediated immunity, cell-mediated immunity or both. However, ordinary vaccines do not offer enough potential to overcome Eimeria species at its full extent. Different research trials and studies have shown that DNA vaccines can induce both antibody and cell-mediated immunity. Several DNA vaccines have been tested in the last few years with marvelous results but still no vaccine is available commercially. Here we will discuss different types of vaccines against Eimeria, especially in poultry. A comparative analysis along with the recent advancements will reveal the types of vaccines that bear sufficient potential to overcome Eimeria species to its full extent. This review will also describe the fruitful and advanced steps towards the synthesis of molecular vaccines in the future. 


\section{Introduction}

Coccidiosis is one of the most prominent and disastrous protozoal diseases of poultry, cause serious threat towards overall health and production. It is caused by species of Eimeria and Isospora, belongs to phylum Apicomlexa, which mostly affects the intestines of birds [1]. It leads towards severe losses as poultry meat and eggs are the cheapest sources of protein, hence contributing a lot to maintain good health and nutritional requirements. This fatal disease affects the overall health and production of birds by disturbing the gut integrity and efficiency of intestines. This condition is followed by poor absorption of feed, low feed conversion ratio, less production of birds and compromised immune system [2]. The decrease in egg production, feed conversion ratio, meat production, and high mortality in poultry sector leads to huge economic losses [3]. There are seven recognized species of genus Eimeria responsible for coccidiosis in poultry and the most important pathogenic species is E. tenella. It affects caecum in birds causing caecal coccidiosis and is responsible for enormous losses to the poultry industry [4].

A lot of methods to confront coccidiosis like chemotherapy and prophylactic measures are in regular practice. Chemotherapy is followed by resistance, which reduces the effects of drugs. Drug residues are also a matter of concern for human consumption [5]. Prophylactic measures have a solid effect on coccidiosis. There are many ways relating to prophylactic measures, which induce immunity against coccidiosis, i.e., vaccination and management betterment. Vaccination is one of the most liable of all techniques to overcome coccidiosis [2]. Live and dead vaccines have a strong impact on immunity. Nowadays, many other new strategies are also contributing to minimizing Eimeria effects. These techniques include subunit vaccines, DNA vaccination and roles of different adjuvants. In this review, we will discuss and analyze all the strategies of vaccination against Eimeria in poultry along with the recent advancements.

\section{Life cycle of Eimeria}

Oocyst of Eimeria remains at different places for many years. Once it sporulates, it becomes active and after ingestion by the specific host, it goes to intestine and exocyst there. Sporozoites released from sporulated oocysts, penetrate the intestinal cells (enterocytes) of the host, encapsulate in a vacuole and replicate [2]. This replication is known as merogony that results in the formation of merozoites. These merozoites are released from the vacuole in tremendous numbers; rupture the host's enterocytes along with invasion into new cells. These merogonic divisions are genetically programmed, depends upon different Eimeria species. The more it reinvades the enterocytes, the more damage it causes, results in severe intestinal lesions $[5,6]$. In the end, merozoites invade the intestinal cells as directed by specie specific merogony and differentiate into gametocytes (male and female gametes). Fertilization occurs within the host's cell; oocytes ruptures the enterocytes and expose to the environment along with feces (Fig 1).

\section{Preventive and prophylactic measures against coccidiosis}

Drugs always possess a central role to alleviate clinical signs of any disease and disease control programs. However, resistance is the main issue towards drug therapy, especially against parasitic infestation in humans and livestock. Every anthelmintic class is followed by resistance, especially in livestock hosts as mentioned by Kaplan [7]. Prophylactic measures have a potent role to escape from parasites. These strategies are followed by their own drawbacks. There should be some novel methods and techniques to eradicate, more or less, to control threats of parasitic infestations. Strategies related to prevention and prophylaxis against coccidiosis are discussed below.

\section{Anticoccidial drugs}

Starting from anticoccidial compounds, the first drug used against coccidiosis was sulphaquinoxaline in 1948 and was approved along with nitrofurazone by American fund and drug administration (AFDA) [8]. Similarly, a lot of drugs were used onwards against coccidiosis without registration and approval with better effects. Later, some drugs were refused by farmers due to resistance and some drugs have their own drawbacks, i.e., safety issues, residues and efficacy [9]. Anticoccidial drugs have different categories like synthetic, polyethylene, ionophores and mixed. Polyethylene or ionophores are further classified into monovalent ionophores, monovalent glycosidic ionophores and divalent ionophores (Table 1). 


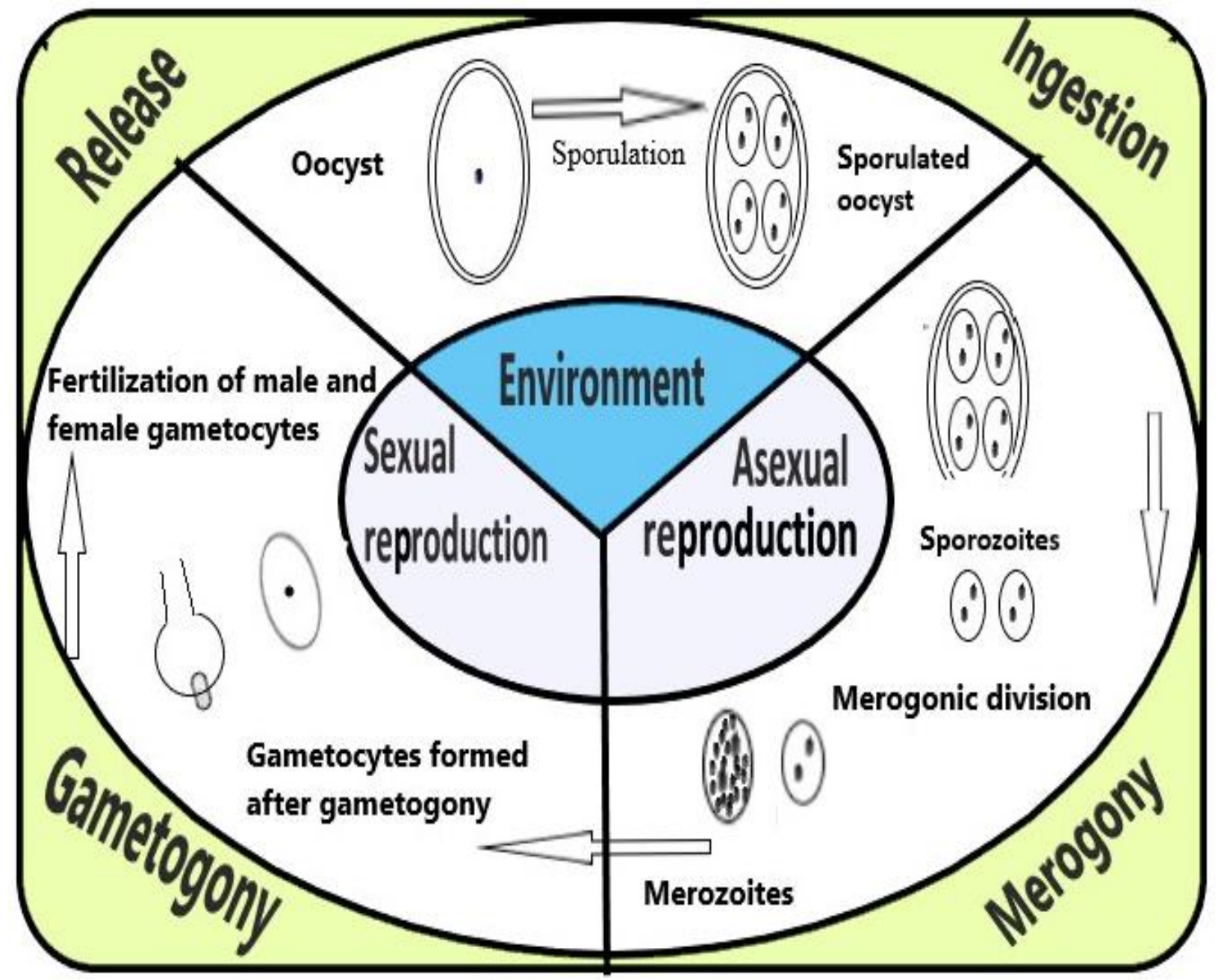

Fig. 1 Different stages of the life cycle of Eimeria tenella.

\section{Resistance}

According to World's Health Organization, resistance against any drug is defined as "The ability of any microorganism/parasite to survive and reproduce itself, instead of having a proper dose of the drug within the tolerance range of host" [10]. Generally, intensive usage of anticoccidial drugs leads to resistance within hosts. Very quick resistance is observed in the case of quinolones and pyridines [11]. Long term exposure to anticoccidial drugs, especially belongs to a single group, leads towards resistance. Even many developed countries like United States (USA), Europe and China bear continuous threats of resistance [12]. A lot of natural herbs and their extracts were also practiced against coccidiosis like Trachyspermum ammi (Ajwain) by Abbas et al. [13] but they have no significance as compared to chemotherapy. These compounds can act a little against some Eimeria species but not all due to huge genetic variability, which degrades their effect $[14,15]$.

\section{Vaccination}

Some necessary prophylactic measures are adopted to confront coccidiosis in which the most important is vaccination. A vaccine is necessary to induce immunity against coccidiosis. Immunity achieved may be active or passive, according to the immune status of the host. Vaccination against Eimeria was first studied by Beach and Corl in 1925 [16], which lead to the foundation of modern vaccines against coccidiosis. Following those strategies, the first commercial vaccine was formulated in 1952 and was registered as coccivac in the USA [17]. After this achievement, a lot of vaccines were formulated by using this technique. Different vaccines were practiced against coccidiosis at different times, which are categorized into different types. A 
detailed study of types of vaccines along with advancement in the vaccination process against Eimeria is as follows:

\section{Live vaccines}

Live vaccines are thoroughly composed of sporulated oocysts, either inactivated (nonattenuated) or inactivated (attenuated) form. Nonattenuated live vaccines consist of wild type strains of Eimeria species. Protective immunity against coccidiosis may be achieved either by applying a single high dose or by trickle infections (applying multiple low doses) [18, 19]. Non-attenuated vaccines contain Eimeria parasites, which are directly obtained from the field area (field strains) without modification and attenuation. Coccivac, immunocox, inovocox and advent are examples of non-attenuated vaccines. It is necessary to provide an equal amount of dose/bird while administering non-attenuated vaccines to avoid the risk of disease occurrence. It is essential to obey proper vaccination protocol in case of live non-attenuated vaccines against Eimeria [20]. Attenuated or inactivated vaccines are those which contain field strains after manipulation or lowering of virulence. There are many ways relating to attenuation like serial passages of parasites within chicken embryo and selection of precocious lines. In Livacox, $E$. tenella is present after treatment with serial passages while other Eimeria species are present by using precocious lines of attenuation process. Paracox contains all Eimeria lines following the precocious lines method of attenuation [21, 22]. Drawbacks of live vaccines are also of considerable importance. The most important is the reduction of effectiveness with the passage of time [23]. Dosage errors also result in non-satisfactory immune response or disease outbreaks. Feed formulations in poultry also contain anticoccidial drugs, which may act as lethal compounds for sensitive strains of Eimeria. Administration of live vaccines to immunocompromised birds may cause an outbreak. Sometimes reversing of virulence related to live, active or attenuated strains of Eimeria may become serious risk for farmers [9].

\section{Subunit vaccines}

This type of vaccine contains antigens that are purified after isolation from virulent and pathogenic Eimeria species. Subunit vaccines may contain antigens or proteins expressed from the DNA of different developmental Eimeria stages, like sporozoites, gametocytes or merozoites. Coxabic is the only registered subunit vaccine, which has been marketed since its manufacturing [24]. The drawback of subunit vaccine is that still, no antigen is able to provoke solid and potent protective immunity. It is necessary to understand the full genomic study of Eimeria, especially of E. tenella to sort out the actual mechanism of the immune response [25].

\section{Exosomes derived from dendritic cells (DC) and antigen-presenting cells (APC) as a vaccine}

Dendritic cells (DCs) were observed as an authentic pathway to induce immunity against coccidiosis. Different chemical signals are activated by DCs, which paved their role to activate T cells. DCs are also known as 'nature adjuvants' and the exosomes derived from these DCs possessing parasitic antigens might become an alternative to produce immunity against coccidiosis [26]. A trial in which the protective immunity was observed against coccidiosis (E. tenella) by using antigen loading DCs and DC-derived exosomes [27]. The study showed that antigen containing cells were present in the lymphoid tissues along with a higher concentration in germinal cells of cecal tonsils and spleen. A higher number of IgG and IgA antibodies were observed within cecal tonsils and spleen cells, reactive with $E$. tenella antigens along with the increased number of IL-2, IL-16, and interferon producing cells as compared to non-vaccinated groups. Similarly, in a research trial, DCs were isolated in vitro from sporozoites of E. tenella, E. acervulina and E. maxima [28]. These DCs were subjected to chickens for immunity induction tests. Results showed that spleen, payer's patches and cecal tonsils possessed a greater amount of IL-2, IL16 and gamma interferon along with antigenstimulated proliferative response and antigen reactive $\operatorname{Ig} \mathrm{A}$ and $\mathrm{IgG}$ producing cells in immunized birds. APC derived exosomes were also studied to check the immune inducing potential. A study determined the immunogenic capabilities of serum exosomes containing parasite antigens against avian coccidiosis [29]. Results revealed that a subset of protein AGS was found, especially in spleen and intestinal areas and an increase in the number of interleukins, especially IL-2, IL-4 and IL-6 along with interferon-gamma secreting cells were also observed in these areas.

\section{DNA vaccines}

It's a novel and magnificent approach towards prophylactic immunity against avian coccidiosis. 
Table 1 Anticoccidial drugs, their categories and mechanism of action.

\begin{tabular}{|c|c|c|c|}
\hline Sr. No. & Anticoccidial drug & Category & Mechanism of action \\
\hline 1 & Amprolium & Synthetic & Competes with parasite for absorption of thiamine (Vit B1) \\
\hline 2 & $\begin{array}{l}\text { Monensin, Narasin and } \\
\text { Salinomycin }\end{array}$ & $\begin{array}{l}\text { Monovalent } \\
\text { ionophores }\end{array}$ & $\begin{array}{l}\text { Interfering balance of ions within parasite, which is very } \\
\text { important for life, like } \mathrm{Na}, \mathrm{K} \text {, etc. }\end{array}$ \\
\hline 3 & $\begin{array}{l}\text { Maduramycin and } \\
\text { Semduramycin }\end{array}$ & $\begin{array}{l}\text { Monovalent } \\
\text { glycosidic ionophore }\end{array}$ & Same as above (Ionophore) \\
\hline 4 & Laslocid & Divalent ionophores & Same as above (Ionophore) \\
\hline 5 & $\begin{array}{l}\text { Maxban (Nicarbazin }+ \\
\text { narasin) }\end{array}$ & Mixed & Dual effect (synthetic + ionophores) \\
\hline 6 & Pyrimethamine & Synthetic & Effects folate pathways of coccidia \\
\hline 7 & Lerbek & Synthetic & Competes with parasite for absorption of thiamine (Vit B1) \\
\hline 8 & $\begin{array}{l}\text { Amprolium }+ \\
\text { Ethophobate }\end{array}$ & Mixed & $\begin{array}{l}\text { Amprolium interferes thiamine, while Ethophobate blocks } \\
\text { para-aminobenzoic acid (PABA) }\end{array}$ \\
\hline
\end{tabular}

DNA vaccine is also known as a third-generation vaccine, which is, in fact, a turning point towards preventive measures against coccidiosis [30] as it provokes cell-mediated immunity, which possesses a magnificent role in immunity [31]. DNA immunization or recombinant antigen can raise both humoral and cellular immune responses and continuous delivery of cytokines and chemokines as potential adjuvants could augment the impending for DNA or recombinant vaccines to induce extreme humoral and cellular immunity [32]. In this technique, immunogenic proteins are first isolated, identified and then inserted into a plasmid (vector); which is most probably a eukaryote, possesses the extreme capability to replicate. After purification of plasmid, the gene is directly inserted into the animal's body. These genes converted into respective proteins after administration, have ability to provoke the host immune system [33]. The selection of genes encoding proteins should be of optimal importance. They must possess any key role in the overall life cycle of Eimeria, i.e., E. tenella microneme protein genes are implicated in parasite recognition, motility, migration, and invasion of host cells [34]. DNA vaccines are more beneficial than all other types of vaccines as they can be generated with more ease and do not need a cold chain for storage. They possess long-lasting stability and they are less dangerous than traditional live vaccines with highly virulent live antigens [2].

\section{Advancements regarding DNA vaccination against Eimeria}

A lot of experimental trials related to DNA vaccines have been performed during the last two decades. In a trial, the respective changes in cytokines and IgG antibodies in serum of chickens were checked after administering a DNA vaccine encoding $E$. acervulina lactate dehydrogenase [31]. The results obtained satisfactorily suggested that this vaccine could raise the $\operatorname{IgG}$ level along with the induction of cytokines expressions. A DNA vaccine was checked against $E$. tenella and induced immunity [35]. In this study, the TA4 gene of E. tenella was ligated with a vector pcDNA3.1/Zeo and administered to experimental chickens. Results indicated that this vaccine-induced sufficient protective immunity against Eimeria challenge. Similarly, a DNA vaccine was prepared using $E$. tenella MZ5-7 gene and checked for the subsequent results against $E$. tenella challenge [36]. The efficacy of a DNA vaccine having $E$. maxima Gam56 as an antigen was determined against chicken coccidiosis [37]. This study indicated that the experimental vaccine could provide partial immunity after challenge with $E$. maxima. In this study, protection and practical application of DNA vaccine were investigated but the mechanisms involved related to the production of immune responses were left for further studies.

\section{Role of different cytokines in DNA vaccine against Eimeria}

There are several factors that mediate innate immunity in the avian immune system. These immune cells recognize the specific pathogenassociated molecular pattern (PAMPS) with the help of their specific pattern recognition receptors. The studies on these immune cells related to coccidiosis and Eimeria species emphasized the extraordinary qualities of these cells, results in the discovery of new uncharacterized genes [38]. A 
vaccine consisting of E. tenella MZ5-7 along with chicken IL-17 was formulated and was evaluated against E. tenella challenge [36]. It was obvious that the vaccine along with cytokine produced more significant immunity then simple vaccines. It was observed that a new class of T-helper cells Th-17 was associated with interleukin IL-17 production. IL-17 works as a potential cytokine stimulator in avian immunity. In a similar study, IL-17 contribution was checked by using experimental $E$. tenella infection and the results showed that chicken IL-17 might help E. tenella induced immunopathology during infection [39]. In another study, E. tenella infected chickens treated with IL$17 \mathrm{~A}$ antibodies suggested that IL-17A stops the migration of parasitized epithelial cells. Furthermore, a significant reduction of ROS and MM-9 along with a marked reduction in cecal lesions was found, which denoted IL-17A as a potential therapeutic agent against coccidiosis [40]. The role of many other cytokines like IL-2, IL-4 and IFN gamma, along with DNA vaccine was also studied. Here it is a special point that must be kept in mind while studying the role of cytokines that 2 different immune responses are governed by 2 different interleukins producing cells. IL-2 and IFN gamma are produced by Th1 cells while IL- 4 and IL- 1 are produced by Th2 cells [41]. All of these cytokines were studied separately and coexpression with different genes. DNA vaccines encoding $E$. tenella gene 541 along with IL-2 and IFN gamma $(I F N-\gamma)$ were studied [42]. The results revealed that antigen 541 possesses good immunogenic qualities along with the confirmation of the role of cytokines that they can boost specific immunity by improving the efficacies of DNA vaccines against avian coccidiosis.

A DNA vaccine was tested in which immunity posed by DNA of E. acervulina cSZ-2 and IL-2 was seen against $E$. tenella challenge [43]. Chickens of one group were vaccinated with pVAX1-cSZ2, pVAX1-IL-2 and $2^{\text {nd }}$ were vaccinated with $\mathrm{pVAX} 1$ cSZ2-IL-2. The results showed that the birds vaccinated with a co-expression of genes and IL2 cytokine depict more tolerance towards E. tenella challenge [43]. A similar trial was exercised, in which a gene encoding protein known as $\mathrm{SO} 7$ was tested for immunogenic analysis along with IL-2 [44]. The results expressed that IL-2 worked as a potential stimulator regarding immunity along with genes as compared to a vaccine containing $\mathrm{SO} 7$ gene alone. The role of IL-2 was also tested [45-47] in which a gene TA4 of E. tenella and pEtK2 gene were used along with IL-2. Results of IL-2 group were significantly protective regarding immunity as compared to other groups [48]. In a recent study, IL-10 was cloned and characterized. IL-10 possesses $45 \%$ identity with human IL-10, while $42 \%$ identical to murine IL-10 [49]. The chIL-10 gene structure contains 4 introns and 5 exons. The data and information gathered in this study revealed a genuine role of chIL-10 in changing Th bias during a protozoan infection [50]. These results showed that IL-10 possesses a solid role to reduce symptoms of Eimeria pathogenesis. One of the most popular works regarding cytokine role in DNA vaccine against Eimeria was done using 8 different cytokines (IL-1 $\beta$, IL-2, IL-8, IL-15, IFN- $\alpha$, IFN- $\gamma$, TGF- $\beta 4$, lymphotactin) as adjuvants along with 3 $1 \mathrm{E}$ gene of $E$. acervulina [51]. Flow cytometry revealed that chickens belong to groups vaccinated with IL-8 and IL-15 adjuvants showed increased numbers of $\mathrm{CD} 3+$ within intraepithelial lymphocytes of the duodenum. Similarly, all other adjuvants also contributed as immune boosters compared to pcDNA-3-1E alone. A chimeric DNA vaccine was examined in which IL-15 was used as an adjuvant along with 3-1E gene. The study proved that antigen $3-1 \mathrm{E}$ linker-mCh $\mathrm{IL}-15$ is more efficient immunologically as compared to antigen 3-1E alone [52].

\section{Available vaccines, now and then}

A lot of formulated available vaccines are there. A brief discussion about these vaccines is given below.

\section{Live non-attenuated anticoccidial vaccines}

\section{Coccivac- $B$}

Coccivac-B is used for heavy broilers and is currently approved in Canada, United States and other countries. It contains $E$. tenella, $E$. Acervulina, E. maxima and E. mivati as nonattenuated antigens. Coccivac-B may be administered via different routes like hatchery spray, feed spray, ocular route and drinking water. The age of birds should be 1 day to 2 weeks [53].

\section{Coccivac-D}

Coccivac-D is used for heavy breeders and layers and is currently approved in Canada, United States and other countries. It contains E. tenella, E. acervulina, E. maxima, E. mivati, E. hagani, E. brunetti, E. praecox and E. necatrix as nonattenuated antigens. It may be administered via different routes like hatchery spray, feed spray, 
ocular route and drinking water at the age of 1 day to 2 weeks [54].

\section{Immисох $\mathrm{Cl}$}

Immucox $\mathrm{C} 1$ is used for roasters and broilers mostly containing non attenuated antigens of $E$. tenella, $E$. acervulina, E. maxima and E. mivati. It is currently approved for Canada, United States and other countries. It can be administered through different routes like oral gel and drinking water. The age of birds should be 1 day to 2 weeks [53].

\section{Imтисох $C 2$}

Immucox $\mathrm{C} 2$ is used for breeders and layers. It contains E. tenella, E. acervulina, E. maxima, E. mivati, E. Necatrix and E. brunetti in nonattenuated form. It is currently approved for United States, Canada and other countries. Mostly administer through different routes like drinking water. The age of birds should be 1 day to 14 days [54].

\section{Inovocox}

Inovocox is used in ova as a single dose in broilers mostly. It contains E. tenella, E. acervulina and two strains of E. maxima in nonattenuated form. It is currently approved for use in United States [53].

\section{Inovocox EMI}

Inovocox EM1 is used as a single dose in ova of broilers mostly. It contains one strain of E. maxima, $E$. tenella and E. acervulina in nonattenuated form. It is currently approved for use in United States [53].

\section{Advent}

Advent is used in broilers mostly. It contains $E$. tenella, E. acervulina and E. maxima in nonattenuated form. It is administered as a single dose as hatchery spray mostly on the day of hatch or first feed as a feed spray. It is currently approved for use in United States [53].

\section{Live attenuated anticoccidial vaccines}

\section{Livacox D}

Livacox D is used in caged chickens mostly. It contains E. tenella and E. acervulina in attenuated form. It is currently approved for use outside of United States and Canada. It is mostly administered in drinking water as a single dose at the age of 1-10 days of birds [54].

\section{Livacox $T$}

It is used in breeders and broilers. It contains $E$. tenella, E. maxima and E. acervulina in attenuated form. It is mostly administered in drinking water and ocular form as a single dose at the age of 1-10 days. It is currently approved for use outside of United States and Canada [53].

\section{Livacox $Q$}

Livacox Q is used in broilers. It contains E. tenella, E. maxima, E. brunetti and E. acervulina in attenuated form. It is currently approved for use outside of United States and Canada. It is mostly administered in drinking water and ocular form as a single dose at the age of 1-10 days [53]

\section{Paracox}

Paracox is used in breeders, layers and broilers. It contains a great combination of E. tenella and two different antigenic strains of E. maxima, E. mivati, E. praecox, E. brunetti and E. acervulina in attenuated form. It is currently approved for use outside of United States and Canada. It is mostly administered in feed spray and drinking water as a single dose at the age of 1-9 days [53].

\section{Paracox 5}

It is used in broilers. It contains a combination of $E$. tenella and two different antigenic strains of $E$. maxima, E. mivati, E. praecox, and E. acervulina in attenuated form. It is mostly administered as hatchery spray, feed spray and drinking water as a single dose at the age of $1^{\text {st }}$ or $3^{\text {rd }}$ day. It is currently approved for use outside of United States and Canada. [53]

\section{Nobilis COX ATM}

Nobilis COX ATM is used in broilers mostly. It contains a combination of $E$. tenella and two different antigenic strains of E. maxima and $E$. acervulina in non-attenuated form. It is mostly administered as hatchery spray and drinking water as a single dose. For hatchery spray, age should be 1-5 days while 4-5 days of age is suitable in drinking water. It is currently approved for use outside of United States and Canada [53]

\section{Subunit vaccines}

\section{CoxAbic}

CoxAbic is the only subunit vaccine that has been marketed until now. Subunit vaccines mainly contain a purified antigen isolated from pathogenic organisms. Subunit vaccines are obtained by different technologies either contain recombinant proteins, antigens or DNA of different developmental stages of Eimeria species. CoxAbic provokes maternally derived antibodies [55]. 


\section{Conclusion}

Eimeria species are a constant threat to poultry production. While chemotherapy leads to many drawbacks, prophylactic measures are of eminent importance but ordinary vaccination can induce antibody-mediated immunity only, which does not offer enough potential to overcome Eimeria species at its full extent. Different research trials and studies have shown that DNA vaccines can induce both antibody and cell-mediated immunity. Several DNA vaccines have been tested in the last few years with marvelous results but still no vaccine is available commercially. It is necessary to take fruitful and advance steps towards the synthesis of molecular vaccines in the future.

\section{Conflict of Interest}

The author declares no conflict of interest in this study.

\section{References}

[1] Lee SH, Lillehoj HS, Jang SI, Lee KW, Yancey RJ, Dominowski P. The effects of a novel adjuvant complex/Eimeria profilin vaccine on the intestinal host immune response against live E. acervulina challenge infection. Vaccine 2010; 39:6498-504.

[2] Shah MAA. DNA vaccines as sustainable Coccidiosis control strategies in chickens. Sci Lett 2013; 1:1-4.

[3] Clark EL, Macdonald SE, Thenmozhi V, Kundu K, Garg R, Kumar S et al. Cryptic Eimeria genotypes are common across the southern but not northern hemisphere. Int J Parasitol 2016; 9:537-544.

[4] Zhou Z, Nie K, Huang Q, Li K, Sun Y, Zhou R, et al. Changes of cecal microflora in chickens following Eimeria tenella challenge and regulating effect of coated sodium butyrate. Exp parasitol 2017; 177:7381.

[5] Idris M, Abbas RZ, Masood S, Rehman T, Farooq U, Babar W, et al. The potential of antioxidant rich essential oils against avian coccidiosis. World Poultry Sci J 2017; 1:89-104.

[6] Ahmad TA, El-Sayed BA, El-Sayed LH. Development of immunization trials against Eimeria spp. Trials Vaccinol 2016; 5:38-47.

[7] Kaplan R. Drug resistance in nematodes of veterinary importance a status report. Trends Parasitol 2004; 20:477-81.

[8] Chapman HD. Biochemical, genetic and applied aspects of drug resistance in Eimeria parasites of the fowl. Avian Pathol 1997; 26:221-44.

[9] Peek HW, Landman WJ. Coccidiosis in poultry: anticoccidial products, vaccines and other prevention strategies. Vet quart 2011; 3:143-61.

[10] World Health Organization. Resistance of malaria parasites to drugs. WHO Technical Report. Geneva, Switzerland: World Health Organization 1965, p. 165.
[11] Zhou R, Nie K, Wang J. The sensitivity test of Eimeria tenella to four anticoccidial drugs. J Sichuan Inst Anim Husb Vet Med 2000; 14:20-23.

[12] Peek HW, Landman WJM. Gevoeligheidsprofielen van Spaanse, Duitse en Nederlandse Eimeria spp. veldisolaten voor anticoccidiose middelen. Tijdschr Diergeneeskd 2004; 129:210-214.

[13] Abbas A, Abbas RZ, Khan MK, Raza MA, Mahmood MS, Saleemi MK, et al. Anticoccidial effects of Trachyspermum ammi (Ajwain) in broiler chickens. Pak Vet J 2019; 39:301-304.

[14] Clark EL, Tomley FM, Blake DP. Are Eimeria genetically diverse, and does it matter? Trends Parasitol 2017; 33:231-41.

[15] Quiroz-Castañeda RE. Avian Coccidiosis, New Strategies of Treatment. In: Farm Animals Diseases, Recent Omic Trends and New Strategies of Treatment: Intechopen; 2018, pp119-80.

[16] Beach JR, Corl JC. Studies in the control of avian coccidiosis. Poultry Sci 1925; 4:83-93.

[17] Edgar SA, King DE. Breeding and immunizing chickens for resistance to coccidiosis. $62 \mathrm{nd}$ and $63^{\text {rd }}$ Annu rep Alabama. Agr Exp Stat 1952; 36-37.

[18] Joyner LP, Norton CC. The immunity arising from continuous low-level infections with Eimeria tenella. Parasitol 1973; 67:907-13.

[19] Long PL, Johnson J, McKenzie ME, Perry E, Crane MS, Murray PK. Immunization of young broiler chickens with low level infections of Eimeria tenella, E. acervulina, or E. maxima. Avian Pathol 1986; 15:271-8.

[20] Chapman HD, Cherry TE, Danforth HD, Richards G, Shirley MW, Williams RB. Sustainable coccidiosis control in poultry production: the role of live vaccines. Int J Parasitol 2002; 32:617-29.

[21] McDonald V, Shirley MW. Eimeria mitis: a comparison of the endogenous development stages of a line selected by early maturation of the parent strain. Parasitology 1984; 88:37-44.

[22] Shirley MW, Bedrnik P. Live attenuated vaccines against avian coccidiosis: success with precocious and egg-adapted lines of Eimeria. Parasitol Today 1997; 12:481-484.

[23] Jeston PJ, Blight GW, Anderson GR, Molloy JB, Jorgensen WK. Comparison of infectivity of Eimeria tenella oocysts maintained at 4,12 or $28^{\circ} \mathrm{C}$ up to 10 months. Aust Vet J 2002; 80:91-92.

[24] Vermeulen AN. Progress in recombinant vaccine development against coccidiosis a review and prospects into the next millennium. Int $\mathrm{J}$ Parasitol 1998; 7:1121-1130

[25] Shirley MW, Smith AL, Blake DP. Challenges in the successful control of the avian coccidia. Vaccine 2007; 25:5540-7.

[26] Shoaib M, Xiaokai S, Ul-Hasan M, Zafar A, Riaz A, Umar S, et al. Role of dendritic cells in immunity against avian coccidiosis. World's Poultry Sci J 2017; 4:737-46.

[27] del Cacho E, Gallego M, Lee SH, Lillehoj HS, Quilez J, Lillehoj EP, et al. Induction of protective immunity against Eimeria tenella infection using antigen-loaded 
dendritic cells (DC) and DC-derived exosomes. Vaccine 2011; 21:3818-25.

[28] del Cacho E, Gallego M, Lee SH, Lillehoj HS, Quilez J, Lillehoj EP, Sánchez-Acedo C. Induction of protective immunity against Eimeria tenella, Eimeria maxima, and Eimeria acervulina infections using dendritic cell-derived exosomes. Infect Immun 2012; 5:1909-16.

[29] del Cacho E, Gallego M, Lillehoj HS, Quilez J, Lillehoj EP, Sánchez-Acedo C. Induction of protective immunity against experimental Eimeria tenella infection using serum exosomes. Vet Parasitol 2016; 224:1-6.

[30] Watts AM, Kennedy RC. DNA vaccination strategies against infectious diseases. Int J Parasitol 1999; 8:1149-63.

[31] Song H, Song X, Xu L, Yan R, Shah MAA, Li X. Changes of cytokines and $\mathrm{IgG}$ antibody in chickens vaccinated with DNA vaccines encoding Eimeria acervulina lactate dehydrogenase. Vet Parasitol 2010; 4:219-27.

[32] Huang J, Zhang Z, Li M, Song X, Yan R, Xu L, et al. Eimeria maxima microneme protein 2 delivered as DNA vaccine and recombinant protein induces immunity against experimental homogenous challenge. Parasitol Int 2015; 5:408-16.

[33] Jazayeri SD, Poh CL. Recent advances in delivery of veterinary DNA vaccines against avian pathogens. Vet Res 2019; 1:78.

[34] Han H, Xue P, Dong H, Zhu S, Zhao Q, Huang B. Screening and characterization of apical membrane antigen 1 interacting proteins in Eimeria tenella. Exper Parasitol 2016; 170:116-24.

[35] Wu SQ, Wang M, Liu Q, Zhu YJ, Suo X, Jiang JS. Construction of DNA vaccines and their induced protective immunity against experimental Eimeria tenella infection. Parasitol Res 2004; 5:332-336.

[36] Xu L, Li X. Vaccination of chickens with DNA vaccine expressing Eimeria tenella MZ5-7 against coccidiosis. Vet parasitol 2011; 2:6-12.

[37] Xu J, Zhang Y, Tao J. Efficacy of a DNA vaccine carrying Eimeria maxima Gam56 antigen gene against coccidiosis in chickens. Korean J Parasitol 2013; 2:147.

[38] Min W, Kim WH, Lillehoj EP and Lillehoj HS. Recent progress in host immunity to avian coccidiosis: IL-17 family cytokines as sentinels of the intestinal mucosa. Develop Comp Immunol 2013; 3:418-28.

[39] Zhang L, Liu R, Song M, Hu Y, Pan B, Cai J, et al. Eimeria tenella: interleukin 17 contributes to host immunopathology in the gut during experimental infection. Experi Parasitol. 2013; 2:121-30.

[40] del Cacho E, Gallego M, Lillehoj HS, Quílez J, Lillehoj EP, Ramo A, et al. IL-17A regulates Eimeria tenella schizont maturation and migration in avian coccidiosis. Vet Res 2014; 1:25.

[41] Lillehoj HS, Lee SH, Jang SI, Kim DK, Lee KW. Recent progress in understanding host mucosal response to avian coccidiosis and development of alternative strategies to mitigate the use of antibiotics in poultry production. Korean J Poultry Sci. 2011; 4:275-84.

[42] Song X, Xu L, Yan R, Huang X, Li X. Construction of Eimeria tenella multi-epitope DNA vaccines and their protective efficacies against experimental infection. Vet Immunol Immunopath 2015; 4:79-87.

[43] Shah MAA, Xu L, Yan R, Song X, Li X. Cross immunity of DNA vaccine pVAX1-cSZ2-IL-2 to Eimeria tenella, E. necatrix and E. maxima. Exper Parasitol 2010; 3:330-333.

[44] Song H, Qiu B, Yan R, Xu L, Song X, Li X. The protective efficacy of chimeric SO7/IL-2 DNA vaccine against coccidiosis in chickens. Res Vet Sci 2013; 3:562-567.

[45] Song X, Xu L, Yan R, Huang X, Shah MA, Li X. The optimal immunization procedure of DNA vaccine pcDNA-TA4-IL-2 of Eimeria tenella and its crossimmunity to Eimeria necatrix and Eimeria acervulina. Vet Parasitol 2009; 1:30-36.

[46] Xu Q, Song X, Xu L, Yan R, Shah, MAA, Li X. Vaccination of chickens with a chimeric DNA vaccine encoding Eimeria tenella TA4 and chicken IL-2 induces protective immunity against coccidiosis. Vet Parasitol 2008; 4:319-23.

[47] Song X, Zhao X, Xu L, Yan R, Li X. Immune protection duration and efficacy stability of DNA vaccine encoding Eimeria tenella TA4 and chicken IL2 against coccidiosis. Res Vet Sci 2017; 111:31-5.

[48] Zhang B, Yuan C, Song X, Xu L, Yan R, Shah MA, et al. Optimization of Immunization Procedure for Eimeria tenella DNA Vaccine pVAX1-pEtK2-IL-2 and Its Stability. Acta Parasitol 2019; 4:745-52.

[49] Rothwell L, Young JR, Zoorob R, Whittaker CA, Hesketh P, Archer A, et al. Cloning and characterization of chicken IL-10 and its role in the immune response to Eimeria maxima. J Immunol 2004; 4:2675-82.

[50] Arendt M, Elissa J, Schmidt N, Michael E, Potter N, Cook M, et al. Investigating the role of interleukin 10 on Eimeria intestinal pathogenesis in broiler chickens. Vet Immunol Immunopath. 2019; 218:109934

[51] Ma D, Ma C, Pan L, Li G, Yang J, Hong J, et al. Vaccination of chickens with DNA vaccine encoding Eimeria acervulina 3-1E and chicken IL-15 offers protection against homologous challenge. Exp Parasitol 2011; 1:208-214.

[52] Min W, Lillehoj HS, Burnside J, Weining KC, Staeheli P, Zhu JJ. Adjuvant effects of IL-1 $\beta$, IL-2, IL-8, IL-15, IFN- $\alpha$, IFN- $\gamma$ TGF- $\beta 4$ and lymphotactin on DNA vaccination against Eimeria acervulina. Vaccine 2001; 2:267-274

[53] Vermeulen AN. Schaap DC and Schetters TP. Control of coccidiosis in chickens by vaccination. Vet Parasitol 2001; 2:13-20.

[54] Williams RB. Anticoccidial vaccines for broiler chickens: pathways to success. Avian pathol 2002; 4:317-353.

[55] Ziomko IR, Karamon JA, Cencek TO, Gornowicz E, Skoracki AL, Ashash AU. Prevention of broiler chick coccidiosis using the inactivated subunit vaccine CoxAbic ${ }^{\circledR}$. Bull Vet Inst Pulawy 2005; 49:299-302. 